\title{
Response to Letter to the Editor: Implications of Celiac Disease Among Patients Undergoing Gastric Bypass
}

\author{
Lindsey M. Freeman ${ }^{1}$ (D) Matthew Kroh ${ }^{2,3,4}$ \\ Published online: 31 August 2018 \\ (C) Springer Science+Business Media, LLC, part of Springer Nature 2018
}

\section{Dear Editor,}

We thank the letter writer as well as the Editorial Board at Obesity Surgery for the opportunity to expand on and strengthen our manuscript, "Implications of celiac disease among patients undergoing gastric bypass." Of the original 68 patients reviewed for abnormal serology or pathology, one had diagnosis of non-celiac gluten sensitivity (NCGS). We suspect this may in part be due to the absence of well-defined diagnostic criteria for NCGS [1, 2], especially given our patient search yielded surgeries as

Lindsey M. Freeman

1xf148@case.edu

Matthew Kroh

krohm@ccf.org

1 Case Western Reserve School of Medicine, Case Western Reserve University, 2109 Adelbert Road, Cleveland, OH 44106, USA

2 Section of Surgical Endoscopy, Department of General Surgery, Cleveland Clinic, Cleveland, OH, USA

3 Lerner College of Medicine of Case Western Reserve University, Cleveland, OH, USA

4 Digestive Disease Institute, Cleveland Clinic Abu Dhabi, Abu Dhabi, United Arab Emirates remote as 2002. No patients had a diagnosis of wheat allergy. The remaining patients had some criteria but not all to fulfill the AGA criteria for celiac disease, and as such, remain with an unspecified other diagnosis.

Funding Information Departmental/instrumental funding supported this research.

\section{Compliance with Ethical Standards}

Conflict of Interest Matthew Kroh has served as a consultant to Medtronic, Levita Magnetics, and Cook, and has received research funding from Cook. The authors declare that they have no conflict of interest.

Ethical Approval Statement This article does not contain any studies with human participants or animals performed by any of the authors. For this type of study formal consent is not required.

Informed Consent Statement Does not apply.

\section{References}

1. Vasagar B, Cox J, Herion JT, et al. World epidemiology of non-celiac gluten sensitivity. Minerva Gastroenterol Dietol. 2017;63:5-15.

2. Elli L, Branchi F, Tomba C, et al. Diagnosis of gluten related disorders: celiac disease, wheat allergy and non-celiac gluten sensitivity. World J Gastroenterol. 2015;21(23):7110-9. 